\title{
(6) OPEN ACCESS \\ "You're made to feel like a dirty filthy smoker when you're not, cigar smoking is another thing all together." Responses of Australian cigar and cigarillo smokers to plain packaging
}

\author{
Caroline L Miller, ${ }^{1,2}$ Kerry A Ettridge, $^{1}$ Melanie A Wakefield ${ }^{3}$
}

${ }^{1}$ SAHMRI Population Health Research Group, South Australian Health and Medical Research Institute, Adelaide, South Australia, Australia

${ }^{2}$ School of Population Health, University of Adelaide, Adelaide, South Australia, Australia

${ }^{3}$ Centre for Behavioural Research in Cancer, Cancer Council Victoria, Melbourne, Victoria, Australia

\section{Correspondence to} Dr Caroline L Miller, SAHMRI Population Health Research Group, South Australian Health and Medical Research Institute, PO Box 11060, Adelaide, SA 5061, Australia; caroline.miller@sahmri.com

Received 24 September 2014 Accepted 5 December 2014

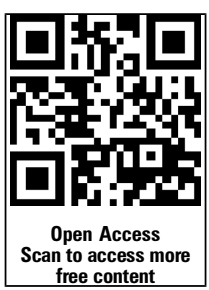

CrossMark

To cite: Miller $\mathrm{CL}$,

Ettridge KA, Wakefield MA.

Tob Control 2015;24:

ii58-ii65.

\section{ABSTRACT}

Objective To explore experiences of cigar and cigarillo smokers under Australian laws requiring plain packaging (PP) and strengthened graphic health warnings (GHWs).

Methods In February/March 2014, we conducted: in-depth interviews with 10 regular premium cigar smokers; two focus groups with occasional premium cigar and premium cigarillo smokers ( $n=14)$; four focus groups with non-premium cigarillo smokers $(n=28)$; and a national online survey of cigar and/or cigarillo smokers $(n=268)$.

Results Premium cigar smokers had limited exposure to $\mathrm{PP}$, with many purchasing fully branded cigars in boxes duty free or online and singles in non-compliant packaging. Those who were exposed noticed and were concerned by the warnings, tried to avoid them and felt more like 'dirty smokers'. Changes in perceived taste, harm and value were minimal for experienced premium cigar smokers. Occasional premium cigar and premium cigarillo smokers with higher PP exposure (gained by purchasing boxes rather than singles) perceived cigar/ package appeal and value had declined and noticed the GHWs. Non-premium cigarillo smokers reported high PP exposure, reduced perceived appeal, quality, taste, enjoyment and value, somewhat increased perceived harm, greater noticeability of GHWs and concealment of packs and more contemplation of quitting. Online survey participants reported increased noticeability of GHWs (33\%), decreased appeal of packaging (53\%) and reduced consumption of cigars (42\%) and cigarillos (44\%) since PP implementation.

Conclusions Non-premium cigarillo smokers appear to have been most exposed and influenced by PP, with cigar smokers less so, especially regular premium cigar smokers who have maintained access to fully branded products.

\section{INTRODUCTION}

Australian legislation requiring all tobacco products to be sold in drab dark brown plain packaging from 1 December 2012, also includes specific requirements for cigars and cigarillos. ${ }^{1}$ Like cigarettes, the new provisions for cigar and cigarillo boxes and packs, and bags for packaging of single cigars for sale prohibit logos, brand imagery and design. They require standardised package colour and standardised font colour and size for brand and variant names. All cigar packaging, other than cylindrical tubes in which cigars can be packaged for sale, are required to display expanded and updated graphic health warnings (GHWs), while cigar tubes must display text only warnings. ${ }^{2}$ For further details see Scollo et al. ${ }^{3}$

In Australia, cigars have been subject to the same marketing restrictions as other types of tobacco with prohibitions on advertising in mainstream broadcast media, retail displays and, in 2012, regulation of online 'point-of-sale' for Australian-based providers. The prevalence of cigar smoking in Australia is low and has not risen in recent decades. It is much lower than other forms of tobacco smoking. The latest national Australian data from 2010 found the combined percentage of survey participants smoking cigars and/or pipes among those who were smokers (aged $14+$ years) was $8 \%$, or approximately $1 \%$ of all participants.

Despite strong regulation of cigar promotion within Australia, Australian legislation does not cover promotion of cigars and other forms of tobacco in imported magazines, online marketing from providers outside Australia, product placement in movies, or promotion via social media, all of which expose the Australian market to cigar promotion.

Many international jurisdictions, including the USA, have fewer restrictions than Australia on tobacco marketing, including cigars. The rise in the popularity of cigar smoking in the USA and elsewhere has led to a focus on the influencing factors, including the increased frequency of cigar content in popular media and the ways in which cigars have been portrayed. ${ }^{5}$ A number of studies observed increases in cigar marketing starting in the 1990 s, increasing the visibility and normalisation of cigar smoking, with associated increases in prevalence of use. ${ }^{6-10}$ Cigar marketing proliferated in print media, social media and other online platforms. Cigars have been consistently positioned as a luxury good, a status symbol and a sign of affluence and power, and as part of a successful, sophisticated lifestyle. ${ }^{11-13}$ Cigars have been promoted with a range of historical and contemporary celebrities and public figures. ${ }^{6} 11-13$ Analyses of print media content have also consistently found that the health effects of cigars have been downplayed and minimised. $^{12}$

In 2011, qualitative research examined the smoking behaviour, attitudes and perceptions of Australian cigar smokers to assist development of plain packaging provisions and GHWs. ${ }^{14}$ Australian cigar smokers reported viewing cigar smoking as a luxury and an indulgence, with higher status attributed to premium cigars.

This research identified differences between cigarillo smokers and lower and higher frequency 
consumers of premium cigars. More frequent premium cigar smokers were found to be extremely knowledgeable about the different types of cigars, regularly smoking different cigar brands. These cigar smokers were also reported to judge the quality of a cigar on criteria including: the type of tobacco; the roll; the age; and the country and region of origin. The brand name was taken as a sign of authenticity or legitimacy of the product. This information was reported to have been included on the cigar band where more frequent cigar smokers looked for these indications of quality.

Less frequent smokers of premium cigars reportedly viewed cigar smoking as an occasional pleasure, associated with particular social occasions or celebrations. They were less knowledgeable than more frequent cigar smokers about premium cigars. These cigar smokers reported taking a stronger interest in the branding and packaging of cigars than did more frequent cigar smokers. The branding and packaging was reported to have a strong effect on their perceptions of quality. Similar patterns were also reported for smokers of premium and non-premium cigarillos, with smokers of non-premium cigarillos reporting being more likely to associate appeal and quality with packaging.

The current research sought to assess, among different segments of cigar consumers: (1) current cigar and cigarillo smoking behaviour and consumers' exposure to new packaging changes; (2) perceived changes relating to the specific objectives of the plain packaging legislation, namely, reduced appeal, increased GHW effectiveness and reduced extent to which consumers are misled about harms; and (3) more 'downstream' perceived changes in smoking behaviours and thoughts since the implementation of plain packaging.

\section{METHODS}

\section{Study design and participants}

Owing to the low population prevalence of cigar smoking and diverse demographic composition of segments of cigar smokers in Australia, this research employed a mixed methods design with qualitative and quantitative components to maximise capture and engagement of different segments of cigar consumers. The methods used in the qualitative studies were closely aligned to pre-plain packaging qualitative research and had proved successful with engaging different segments of cigar smokers. ${ }^{14}$ Based on this previous research experience, ${ }^{14}$ a focus group methodology was not considered to be a viable approach to recruit and/or engage regular premium cigar smokers; a group which is quite distinct from other cigar/cigarillo smokers in that they were of higher socioeconomic status and placed higher value on their time. However, collecting data via structured interviews had been successful with this group. Thus, structured interviews were employed for the regular premium cigar smokers, and group discussions were employed for the other cigar and cigarillo smokers. An online survey enabled quantitative data collection from a substantial general sample of cigar and cigarillo smokers.

Participants in the qualitative studies were recruited through an accredited recruitment specialist with access to databases of individuals who had already indicated a willingness to be contacted for the purpose of research, using Interviewer Quality Control Australia (IQCA) standards. Current smokers were identified from the database, and were administered a recruitment screening survey either online or by telephone. Eligible participants were encouraged to pass on the details of the study to others who fit the selection criteria. All studies included participants who were 18 years or older and proficient in English and all qualitative study participants completed a consent form prior to participation.

We first conducted in-depth interviews of 40-50 min duration with premium cigar smokers $(\mathrm{n}=10)$, defined as those who smoked a premium cigar (costing $\$ \mathrm{~A} 25+$ ) at least once a week. We then ran two sets of focus groups. The first set consisted of occasional (fortnightly or monthly) premium cigar smokers and/or premium cigarillo smokers ( 2 groups, total $n=14$ ). The second set included non-premium cigarillo smokers (4 groups, total $\mathrm{n}=28$ ). All focus groups were $1 \mathrm{~h}$ in duration. All qualitative research was conducted in Sydney and Melbourne in February 2014.

Finally, in March 2014 we conducted an online survey (510 min duration) of a general national sample of current cigar and cigarillo smokers $(n=268)$. This sample was recruited from an existing national online panel who had expressed their willingness to be contacted for the purpose of research. This panel develops their database from a number of sources including advertising and 'word-of-mouth'. A total of 56589 email invitations describing the nature of the study (ie, to gather information regarding people's views and experiences about smoking cigars and other tobacco products) were sent out to randomly selected members of the online panel, of which 5761 started the survey (response rate of 10\%). Only 283 of these participants (ie, 5\% of the people who started the survey) met the eligibility criteria as assessed by screening questions at the beginning of the survey, that is, they were aged 18 years or older and reported that they currently smoked either cigars and/or cigarillos, with a further 15 excluded due to incomplete responses, leaving 268 participants in the sample.

\section{Research materials}

Semistructured discussion guides were used for the qualitative studies, comprised of: general introduction; existing smoking and purchasing behaviour; relationships with brands (if any); views on plain packaging; reactions to GHWs; and intentions to quit. Participant self-completion forms including pictorial examples of plain packaging and GHWs were used as stimulus material.

The online survey used questions adapted from existing tobacco control monitoring surveys where available and new, survey-specific questions where necessary, with response options informed by the qualitative research. Questions addressed tobacco use, purchasing behaviour, cigar/cigarillo specific smoking behaviour, brand choice and preferences, recall and perceptions of plain packaging and GHWs on cigars/cigarillos; and self-perceived changes in beliefs and behaviour since the implementation of plain packaging.

\section{Analyses}

Two researchers moderated the focus groups and conducted the interviews. A thematic analysis model was used to analyse the qualitative data. The two researchers on the project contributed to this analysis by independently referring to the data sources (transcripts, notes and the self-completion forms). Each developed and tested hypotheses based on the interviews and group discussions they conducted, and identified emergent themes and patterns. Following this, these researchers participated in several debriefing sessions to discuss the analysis and results, to reach consensus on potential themes using all the data relevant to each and to identify frameworks for further in-depth analysis. On-going analysis and revision of data sources was conducted to ensure coding consistency, to refine the specifics of each theme, to strengthen within-theme coherence, to ensure evidence of saturation and to ensure the credibility of the data with the 
research objectives. This was an iterative process that continued throughout the writing of the results.

Data from the online survey were analysed using IBM SPSS Statistics V.22. For continuous variables, means and SDs were calculated, and frequencies are reported for categorical data. Small cell sizes prevented more complex analyses.

\section{RESULTS}

Table 1 summarises the samples for each of the three studies, and table 2 summarises the results for each study.

\section{In-depth interviews of regular premium cigar smokers}

Of the Regular (at least weekly) premium cigar smokers, half also smoked cigarettes. Among these dual-product smokers, each product was claimed to fulfil a different need. Cigar smoking was considered to be more a choice and an enjoyment, while cigarette smoking was considered more of an addiction and fulfilling a physiological need.

Cigarettes have become more of a habit and just satisfying an urge. Cigar smoking is about the smoking... about that very rich taste.

For most, cigar smoking was driven by a specific, regular occasion, for example, 'whisky' or 'card' nights with friends, end of working week, or to have some 'time out'. Owing to the cost of the cigars, cigar smoking was also perceived to provide a sense of exclusivity, prestige and sophistication.

We do poker nights, it's a boys club - meet weekly. The host will have a good bottle of scotch or bourbon. It began with a few of the boys who were settling down and getting married - they wanted to keep up the lifestyle with no family around.

Smoking cigars is more of a treat for me at the end of a week. Or if I've had a busy day and I just want to go home and relax.

There was a general perception that the lower frequency of cigar smoking compared to cigarette smoking, resulted in a low relative risk of health concerns.

I've always believed, and I could be entirely wrong, that cigars aren't as bad for you as cigarettes.

I would never have thought lung cancer. I would have related that to inhaling the smoke which I don't do.

The longer-term cigar smokers bought cigars by the box via planned online and duty free purchases; whereas more occasionbased smokers made opportunistic purchases, usually from a retailer or tobacconist. All regular premium cigar smokers had a

Table 1 Characteristics of samples

\begin{tabular}{|c|c|c|c|c|}
\hline & \multicolumn{3}{|l|}{ Qualitative } & \multirow{2}{*}{$\begin{array}{l}\text { Quantitative } \\
\text { 4. Cigar and cigarillo } \\
\text { smokers }(n=268)(\%)\end{array}$} \\
\hline & $\begin{array}{l}\text { 1. Regular premium } \\
\text { cigar smokers }(n=10)\end{array}$ & $\begin{array}{l}\text { 2. Occasional premium cigarl } \\
\text { premium cigarillo smokers }(n=14)\end{array}$ & $\begin{array}{l}\text { 3. Non-premium cigarillo } \\
\text { smokers }(n=28)\end{array}$ & \\
\hline \multicolumn{5}{|l|}{ Gender } \\
\hline Female & 2 & 2 & 8 & 48 \\
\hline Male & 8 & 12 & 20 & 52 \\
\hline \multicolumn{5}{|l|}{ Age group } \\
\hline $18-24$ & - & 3 & 3 & 12 \\
\hline $25-34$ & 1 & 5 & 8 & 29 \\
\hline $35-44$ & 3 & 2 & 5 & 19 \\
\hline $45-54$ & 3 & 3 & 9 & 24 \\
\hline $55+$ & 3 & 1 & 3 & 16 \\
\hline \multicolumn{5}{|c|}{ Frequency of smoking cigar/cigarillos } \\
\hline Daily & 2 & 1 & 3 & $9^{*}$ \\
\hline At least weekly & 8 & 1 & 9 & $14^{*}$ \\
\hline $\begin{array}{l}\text { Fortnightly (qualitative)/less } \\
\text { than weekly (quantitative) }\end{array}$ & - & 4 & 9 & $71^{*}$ \\
\hline Monthly & - & 6 & 4 & NA \\
\hline Less than monthly & - & 2 & 3 & NA \\
\hline \multicolumn{5}{|l|}{ Packaging purchased } \\
\hline Boxed or mostly boxed & 4 & 3 & 15 & $55^{*} \dagger$ \\
\hline Single or mostly single & 4 & 2 & 9 & $60 *+$ \\
\hline Both equally & 2 & 9 & 4 & NA \\
\hline \multicolumn{5}{|c|}{ Tobacco smoked (multiple response) } \\
\hline Cigarettes (factory made) & 5 & 8 & 19 & 79 \\
\hline Roll your own cigarettes & - & 3 & 10 & 62 \\
\hline Cigarillos & 2 & 6 & 28 & 44 \\
\hline Cigars & 10 & 12 & 14 & 94 \\
\hline
\end{tabular}


Table 2 Summary of results across the four participant groups

\begin{tabular}{|c|c|c|c|c|}
\hline & \multicolumn{3}{|l|}{ Qualitative } & \multirow{2}{*}{$\begin{array}{l}\text { Quantitative } \\
\text { 4. General sample of cigar or } \\
\text { cigarillo smokers } \\
(n=268)\end{array}$} \\
\hline & $\begin{array}{l}\text { 1. Regular premium cigars } \\
\text { (interviews) }\end{array}$ & $\begin{array}{l}\text { 2. Occasional premium cigars and } \\
\text { premium cigarillo smokers } \\
\text { (groups) }\end{array}$ & $\begin{array}{l}\text { 3. Non-premium cigarillos } \\
\text { (groups) }\end{array}$ & \\
\hline \multicolumn{5}{|c|}{ Perceived impact of plain packaging } \\
\hline Exposure & $\begin{array}{l}\text { Half seen; half unaware } \\
\text { Purchasing from many } \\
\text { channels }\end{array}$ & $\begin{array}{l}\text { Mixed, low in young purchasing } \\
\text { singles, higher for boxes }\end{array}$ & High exposure & $\begin{array}{l}\text { Recall of any cigar GHWs } \\
(50 \% ; \pm 6 \% \mathrm{Cl}) \\
\text { - Last purchase was compliant } \\
\text { with plain packaging and/or } \\
\text { GHWs } \\
(46 \% ; \pm 6 \% \mathrm{Cl}) \\
\text { Smoked only compliant in past } \\
6 \text { months }(48 \% ; \pm 6 \% \mathrm{Cl})\end{array}$ \\
\hline $\begin{array}{l}\text { Appeal of } \\
\text { packaging }\end{array}$ & $\begin{array}{l}\text { Reduced if exposed (for box and } \\
\text { bag) }\end{array}$ & Reduced among those few exposed & Greatly reduced & $\begin{array}{l}\text { 53\% lower packaging appeal } \\
( \pm 6 \% \text { CI) (12\% higher; } 35 \% \\
\text { same) } \\
28 \% \text { lower product appeal }( \pm 5 \% \\
\text { Cl) }(12 \% \text { higher; } 60 \% \text { same })\end{array}$ \\
\hline Perceived quality & $\begin{array}{l}\text { Minimal change, relied less on } \\
\text { pack }\end{array}$ & Unsure, packaging is a cue for quality & Reduced & $\begin{array}{l}16 \% \text { lower ( } \pm 4 \% \text { Cl) } \\
\text { (15\% higher; } 69 \% \text { same) }\end{array}$ \\
\hline $\begin{array}{l}\text { Changes in taste, } \\
\text { enjoyment }\end{array}$ & Minimal & Minimal for experienced smokers & Reduced & $\begin{array}{l}19 \% \text { lower }( \pm 5 \% \mathrm{Cl}) \\
(15 \% \text { higher; } 66 \% \text { same })\end{array}$ \\
\hline Perceived harm & Low & Lower than cigarettes & Somewhat increased & $\begin{array}{l}19 \% \text { higher ( } \pm 5 \% \text { Cl) } \\
\text { (15\% lower; } 66 \% \text { same) }\end{array}$ \\
\hline Perceived value & Unchanged (less price sensitive) & Reduced, pack part of value & $\begin{array}{l}\text { Reduced, noted tax increased } \\
\text { too }\end{array}$ & $\begin{array}{l}41 \% \text { lower }( \pm 6 \% \mathrm{Cl}) \\
(18 \% \text { higher; } 41 \% \text { same })\end{array}$ \\
\hline Notice Warnings & $\begin{array}{l}\text { High if exposed, especially } \\
\text { graphics }\end{array}$ & High if exposed, especially graphics & High, especially graphics & $\begin{array}{l}33 \% \text { more often }( \pm 6 \% \mathrm{Cl}) \\
\text { (16\% less often, } 43 \% \text { same) }\end{array}$ \\
\hline $\begin{array}{l}\text { Reported } \\
\text { behavioural } \\
\text { changes }\end{array}$ & $\begin{array}{l}\text { Decant from box } \\
\text { - Retail purchasing made them } \\
\text { feel closer to "dirty smokers" }\end{array}$ & $\begin{array}{l}\text { Decant from box } \\
\text { - Less brand trialling }\end{array}$ & $\begin{array}{l}\text { Conceal packs, less brand } \\
\text { trialling, contemplating quitting }\end{array}$ & $\begin{array}{l}\text { Consumption changes since } 2 \text { years } \\
\text { ago: } \\
\text { Cigars: } 42 \% \text { less; } 13 \% \text { more; } \\
45 \% \text { same } \\
\text { Cigarillos: } 44 \% \text { less; } 15 \% \text { more; } \\
42 \% \text { same } \\
\text { Deliberately concealed or decanted: } \\
11 \% \text { more often }( \pm 4 \% \text { Cl) } \\
\text { ( } 21 \% \text { less often; } 56 \% \text { same })\end{array}$ \\
\hline
\end{tabular}

preferred brand; however, trying new brands was part of the experience.

I change brands for something different. I might buy a more expensive brand as a treat.

While brand name and quality packaging contributed to the cigar smoking experience, they reportedly did not shape perceived quality among these experienced premium cigar smokers.

Half of premium cigar smokers reported that they had been exposed to cigar plain packaging, with the others unaware that the legislation applied to cigars. Those exposed indicated that plain packaging and GHWs on the boxes had reduced the appeal of the cigar box. Perceptions of the actual product and experience were not reported to have changed, as they did not attribute the quality of the product to the packaging. Consistent with this, there was also no reported perceived change in value for money.

All the health warnings on it, it's designed to entice you not to smoke. When you open the box, it's like a box of goodies! ... At the end of the day, that's what you want!

The GHWs on bags (required by health warning legislation for single cigar purchases) had reportedly detracted from the experience of purchasing singles among these premium cigar

smokers and counteracted the feelings of reward, prestige and sophistication that were often experienced during the purchase of a cigar. When purchasing from places other than tobacconists, there was some concern that they would be subject to the same social stigma that was directed towards smokers.

\begin{abstract}
You're made to feel like a dirty filthy smoker when you're not, cigar smoking is another thing all together. It's not like cigarettes and it puts it in the same category. It makes a cigar smoker feel like they are doing something wrong, that it's a dirty habit like smoking.
\end{abstract}

Those exposed to plain packaging and GHWs via cigar boxes no longer left the box where it could be seen by others and those with a humidor decanted individual cigars to the humidor whereas some had previously placed the whole box in the humidor.

I keep them in the box in the drawer...I remember in the old days you'd get the big cigars with the nice flash boxes, they'd be all colourful with no warnings on it, and then you'd keep the box out. 


\section{Focus group discussions with occasional premium cigar smokers and premium cigarillo smokers}

This group of occasional (less than fortnightly/monthly) premium cigar and premium cigarillo smokers was comprised of younger people relatively new to smoking premium cigars and cigarillos, as well as older smokers who were quite similar in reported smoking situations to regular premium cigar smokers. Among younger cigar/cigarillo smokers, smoking behaviour was reportedly largely opportunistic.

If guys have them at parties and they offer you one. (I'll have one)

(At the bar) Normally they have four options - I always get the chocolate flavoured one. They're the best!

Smoking cigars/cigarillos occurred in a more public environment as a sign of symbol or status and the product and packaging of cigarillos was considered to establish the smokers as different to an average 'cigarette' smoker. Older occasional premium cigar/cigarillo smokers reported behaviour very similar to regular premium cigar smokers, that is, smoking cigars at a regular social activity, an impending occasion or by themselves at home, and they usually had a preferred brand. They also associated a sense of exclusivity, prestige and sophistication with smoking cigars.

(Cigars have) a refined image. Bit of a boss look. Prestige, wealthy.

I think there's an element of perceived class with cigars and cigarillos. Whereas you're almost a junkie if you smoke cigarettes!

It's cooler than a cigarette.

Many of the smokers within this sample had limited knowledge about how to determine the quality of the cigars compared with regular premium cigar smokers. However, the experience they did have gave them some familiarity with brands and the other factors that were perceived to indicate the quality of the product, making them less subject to packaging as a way to determine quality. Younger, less experienced, smokers were particularly guided by visual cues such as cigar size, packaging and price.

I tend to look at the price.

If you take one out of those tubes, you think, oh, this is going to be good.

(packaging)...it establishes the brand.

Both younger and older occasional cigar/cigarillo smokers were cognisant that cigar smoking could cause harm to their health. However, all held the perception that the comparatively low frequency of cigar smoking compared to other tobacco products resulted in low relative risk.

Cigars are much better 'cause they only give you mouth cancer as opposed to 'everything else' cancer! (like cigarettes)

Because you don't have them too often, no-one's going to be like 'you should slow down on that.'

Exposure to cigar plain packaging was relatively low consistent with the popularity of single cigar/cigarillo only purchases among this group, particularly among the younger smokers.

You can get them online...They come in silver tubes... I've never seen the green (sic) packaging.

They just give it to you how it is. (when purchasing from bars)
Exposure to plain packaging and GHWs was greater among the more experienced occasional cigar/cigarillo smokers who purchased cigars or cigarillos by the box, or who were purchasing multiple singles at a time.

Instead of buying a nice quality, beautiful cigar, you get some health warning that reminds you that if you smoke this you're gonna die. I guess it does take away from the enjoyment a little bit.

These participants reported that they had made changes to how they stored their cigars since the implementation of plain packaging, that is, those with a humidor decanted individual cigars to the humidor rather than the whole box.

I always move the cigars out of the box into my humidor. I used to keep the boxes 'cause they were quite cool.

Now you don't want to look at the boxes - they're just disgusting!

Lack of exposure to plain packaging and relatively limited experience and knowledge of cigars and cigarillos meant that younger occasional smokers of these products were limited in their capacity to discuss their perceptions of markers of quality of cigars. However, the discussion in the groups indicated that packaging was often a key feature on which they rely to make decisions about the quality of the product they were consuming.

Packaging...if it looks nice, you think the cigar will be nicer.

I want to pay for good packaging. I want to get excited about it!

Now when you go to the tobacconist and it's all in that packaging, you don't know what to pick and it's difficult to go with a particular brand based on its prestige and the way it looks.

I hate the packaging. I can't stand it!

The words have no impact on me - it's the images. Because the cigar smoke's in your mouth most of the time.

Plain packaging appeared to have less impact on more experienced smokers' perceptions of quality and product than others, as they reported relying on brand name, reputation, acquired knowledge and recommendations to determine quality. They did not perceive changes in brands since plain packaging in terms of quality, taste, product or value for money.

You used to be able to go in and browse. The ability to do that has decreased enormously... the way they're packaged, displayed. You have to go in already knowing what you're going to buy. I've given up browsing.

Once you get rid of the box and start smoking it, the romance comes back!

\section{Focus group discussions with non-premium cigarillo smokers} Among this group of non-premium cigarillo smokers, consumption of non-premium cigarillos varied from daily to monthly (or less) and many felt cigarillo consumption regulated their cigarette consumption.

I smoke them because when I do, I don't smoke nearly as many as I do when I'm smoking cigarettes.

Smoking cigarillos was part of their routine to mark a point in time, usually the afternoon or evening for relaxation. They often smoked alone; however, some enjoyed cigarillos in a social setting.

After dinner, I'm ready to smoke them after a good meal. 
For those non-premium cigarillo smokers who smoked in social settings, cigarillos were reportedly smoked as part of their personal image.

You feel like you're more sophisticated than the average smoker.

Non-premium cigarillo smokers perceived cigarillos to be more natural and less harmful than cigarettes.

Cigarillos and cigars are obviously a more natural product whereas cigarettes are way too much junk these days.

It's this little pleasure and doesn't do that much harm.

All non-premium cigarillo smokers were highly brand loyal and only familiar with one or two brands, with limited knowledge of the factors that differentiate brands beyond the taste. They reported little interest in trying new or different kinds of cigarillos due to the lack of visual cues to determine possible quality and therefore, the risk of disappointment.

I just smoke the one brand, it's a popular brand ... and I stick to it not knowing anything about others.

If you want to try something different and you're only getting 10 cigars for $\$ 10$ or $\$ 20$ then it's a risk...You don't want to pay all that $\ldots$ and hate it.

These smokers reported a high level of exposure to plain packaging both of cigarillos and cigarettes. Some non-premium cigarillo smokers who had been exposed to plain packaging were convinced that the product was not equivalent to that purchased before the implementation of the legislation, describing perceived changes in flavour, taste, size and 'tightness' of the roll.

I don't smoke them in the new packs because they taste awful ... they are completely different.

Captain Black have shrunk by a third and they taste disgusting, very artificial ... before they had a distinct cherry taste.

Many of the non-premium cigarillo smokers who had seen the GHWs repeatedly acknowledged that the images and warnings had prompted them to think about the product's harm. Self-reported changes in the behaviour of non-premium cigarillo smokers included keeping cigarillo packaging out of sight from others, turning over the pack, averting their eye from the graphic images and warnings, decanting the cigarillos into an unbranded tin, changing brands and intentionally buying from non-compliant retailers. Plain packaging and GHWs were reported to have reduced perceived sophistication associated with non-premium cigarillos and increased participants' tendency to consider the health impacts of smoking cigarillos and to re-evaluate and/or change their smoking behaviour.

It's psychological, it just puts me off ... definitely with normal cigarettes.

The tongue cancer ones worried me a bit, that was the one I saw first and I worried a bit about what it could do to me. It was at a time when I was thinking about smoking them more regularly and so you could say it made me cut down a bit.

Cigarillos used to be in the beautiful boxes, now it's all generic greeny (sic) colour ... it really puts you off.

Before they used to look like a box of chocolates and now ...

You just want to keep it hidden in your pocket.... You don't want rotten teeth looking at you.
Cigars are supposed to be a classy experience ... you don't want to be reminded... and they detract from the overall experience... Before it was pleasurable, now we have to put up with these terrible packs.

\section{Online survey of cigar and cigarillo smokers}

Among this general sample of cigar and cigarillo smokers, nearly all smoked cigars (table 1), with just under half also smoking cigarillos, and most smoking cigarettes (and a very small proportion smoking only cigarillos). This was largely a sample of less frequent cigar smokers and only a small proportion smoked premium cigar/cigarillos (11\%). Participants most commonly reported that they purchased their last cigar or cigarillo from tobacconists (43\%), with fewer purchasing from other sources (9\% bars; 7\% duty free/overseas; 3\% internet).

Half of the participants $(50 \%)$ reported smoking cigars and cigarillos for a special occasion; while approximately one-third reported smoking with a friend (31\%), a group of friends (33\%) and at home (33\%); and fewer reported smoking cigars and cigarillos alone (22\%), at a pub/bar (16\%) or at a cigar bar/ lounge (15\%).

Cigar smokers $(n=251)$ most commonly reported that they liked smoking cigars for relaxation (47\%), taste (46\%) and celebratory purposes (37\%). Benefits of smoking cigars were perceived to be: not as harmful as cigarettes (30\%); a good thing to do with friends (26\%); a way of having time out for themselves (24\%); a sense of sophistication (17\%), exclusivity (16\%), prestige (16\%), and acceptance $(6 \%)$, and few reported it was a hobby/interest (9\%).

Cigar smokers reported strong brand loyalty with 1 (32\%) or a few (38\%) preferred brands, even if they sometimes tried other brands. Furthermore, for most $(81 \%)$ with a brand preference, it was the same as it was 2 years ago. Half (or more) of the sample perceived different cigar and cigarillo brands to differ in taste, prestige and quality. Many of these participants used the taste $(68 \%)$ and smell $(61 \%)$ of the cigar as indicators of quality. Other indicators were: country of origin (51\%), price (41\%), brand name $(35 \%)$, appearance of cigar (33\%) and packaging (15\%).

Approximately one-third (30\%) of the sample believed that cigars and/or cigarillos were less harmful than cigarettes, $47 \%$ believed they caused the same amount of harm and small proportions believed they were more harmful (13\%) or did not know (10\%). Levels of unprompted knowledge regarding illnesses associated with cigars and cigarillos (that were featured on the GHWs) was low among this sample, with 38\% saying lung cancer was caused by cigar/cigarillo smoking, $11 \%$ throat cancer, $10 \%$ mouth cancer, and 2\% mentioning gum disease or damaged teeth.

Exposure to cigar and/or cigarillo plain packaging was reported consistently by approximately half of participants (table 2), in terms of purchasing and smoking cigar/cigarillos that had come in compliant packaging and recalling any one of the cigar/cigarillo specific GHWs.

While participants most commonly reported that the product they currently smoked was 'about the same' as they smoked 2 years ago in terms of 'taste', 'appeal', 'satisfaction', 'quality' and 'harmfulness', over half of the sample reported that the 'appeal of packaging' was lower and over a third reported that 'value for money' was also lower (table 2).

Participants were most likely to report that the frequency with which they experienced a range of smoking thoughts and behaviours had not changed since 2 years ago. However, they 
also reported that they were slightly more likely $(33 \%$ as opposed to less likely $(16 \%))$ to notice the health warnings.

\section{DISCUSSION}

The low population prevalence of cigar smoking in Australia posed challenges for the research. A mixed qualitative and quantitative research methodology enabled quantitative data collection from a substantial sample of cigar and cigarillo smokers, complemented by the in-depth insight into thoughts, perceptions and behaviours of cigar and cigarillo smokers from the qualitative interviews and focus groups.

The primary limitations of this study are the representativeness of the samples and the accuracy of self-report measures, most notably recall. Samples in all studies are not necessarily representative of the population. Participants were asked to compare current thoughts, behaviours and attitudes to those they had experienced 2 years ago, which poses a risk of inaccuracy. However, in a postintervention only study design, this is the most appropriate way to gauge reported changes.

Other factors to consider in the interpretation of the results are social desirability and political sensitivities. Overall, care was taken in the ordering and framing of questions and discussion prompts to minimise socially desirable responses. Plain packaging legislation received considerable industry-driven and general media coverage during its inception. Participants may not have supported plain packaging and GHWs. Support for regulatory measures to curb tobacco consumption often receive less support from smokers than non-smokers, ${ }^{15-17}$ and this was observed for plain packaging in a 2010 study conducted in Western Australia. ${ }^{16}$ However, during the transition to plain packaging, cigarette smokers who were smoking from plain packs had higher approval of the legislation than those still smoking from fully branded packs; ${ }^{18}$ and support for plain packaging increased significantly from preimplementation to postimplementation among a population-based sample of Australian smokers. ${ }^{19}$ This pattern of differences in approval and increases in support postimplementation are similar to those observed when smoke-free laws and display bans have been implemented. ${ }^{20-22}$ Where possible, questions were not framed in the context of plain packaging, however, it was necessary in some instances to ask participants to recall perceived changes since its implementation. Some participants may have been unaware of or reluctant to make attributions about the influence of plain packaging and GHWs on their perceptions, thoughts and behaviours.

A major strength of this research is the in-depth insight it provides into the attitudes, perceptions and behaviours of the hard-to-reach group of cigar smokers. Furthermore, the online survey yielded a substantial sample of cigar/cigarillo smokers and there were some similarities observed across the study samples. A key consistent finding was the variable exposure to new packaging requirements. Furthermore, there were reports of products in non-compliant packaging in most of the samples, although the extent of non-compliance was difficult to quantify. This makes it difficult to determine the full effects of plain packaging as even for those reporting exposure, there may not have been consistent exposure to plain packaging and GHWs. When exposure had occurred, plain packaging and GHWs were attributed to have impact, most notably on non-premium cigarillo smokers who reported the highest exposure, but in all samples, the new packaging reduced perceived packaging appeal and increased noticeability of warnings.

Another notable finding was that perceptions of cigars and cigarillos were often consistent with the ways in which they have been marketed internationally, despite there being strong measures restricting marketing from sources originating in Australia. This most likely reflects the historical influence of many decades of cigar marketing and the contemporary, global reach of social media and online marketing. Unlike the USA and elsewhere, ${ }^{8}$ where cigar marketing is far less regulated, Australia has not seen the rise in prevalence of use in young people or overall. Views that cigar smoking was associated with prestige, status and exclusivity were common, as were reports that cigars and cigarillos were for 'relaxation' and 'time out for oneself'. Cigars and cigarillos were consistently viewed as less harmful and distinct from cigarettes, all of which is consistent with the way cigars have been positioned. ${ }^{611-13}$ There were several indications that plain packaging and new GHWs were challenging views that cigars were less harmful. There were also strong indications that plain packaging and GHWs were substantially reducing the perceived distinctions in prestige and desirability between cigars and cigarettes for cigar smokers. This is a key finding highlighting the influence of plain packaging and GHW, and suggests a need to ensure tobacco control measures aimed at cigarettes include cigars.

Self-reported changes in perceptions and behaviours since the implementation of plain packaging differed between groups and studies, although there were many positive indicators that exposure to GHWs and plain packaging may have increased the frequency of self-reported quitting thoughts and behaviours. For example, online survey participants reported changes in smoking behaviour such that they currently smoked less often than they had 2 years ago.

Other self-reported behaviour changes were documented in only some studies. For example, perceived increases in the frequency of decanting cigars was a prominent finding in the qualitative studies, but participants in the online survey did not report that they were decanting their cigars and/or cigarillos more often than they did 2 years ago. This may be due to data collection methods, for example, group discussions may have prompted more accurate recall, or different behaviours may be observed among the different samples.

Overall, the studies provide useful insight into the smoking thoughts, attitudes and behaviours of the samples of cigar and cigarillo smokers, as well as evidence that when exposure occurred, plain packaging influenced these smokers in ways that were consistent with the specific objectives of the legislation.

\section{What this paper adds}

- Perceptions of cigars and cigarillos were often consistent with the ways in which they have been marketed.

- There was incomplete exposure to Australian plain packaging and graphic health warnings (GHWs) on cigars and cigarillos; with reported exposure seemingly highest among non-premium cigarillo smokers.

- When exposure occurred, there were many positive indicators that GHWs and plain packaging meets tobacco control objectives; with premium cigar smokers also indicating some fear of being equated with cigarette smokers.

Acknowledgements The authors would like to acknowledge Victoria Parr and Margie Lane for qualitative data collection and the provision of qualitative data analysis.

Contributors CLM designed the study. KAE cleaned data files, undertook analysis and reported results. MAW provided advice on study design and interpretation of results. CLM drafted the manuscript with contributions from all authors. All authors approved the final manuscript. 
Funding This study was funded under a contract with the Australian Government Department of Health.

Competing interests The authors wish to advise that $\mathrm{CM}$ and $\mathrm{MW}$ were members of the Expert Advisory Committee on Plain Packaging that advised the Australian Department of Health on research pertaining to the plain packaging legislation. MW holds competitive grant funding from the Australian National Health and Medical Research Council, US National Institutes of Health, Australian National Preventive Health Agency and BUPA Health Foundation. CM and MW hold such grant funding from Cancer Council South Australia.

Ethics approval The University of South Australia Human Research Ethics Committee provided approval for this research.

Provenance and peer review Not commissioned; externally peer reviewed.

Open Access This is an Open Access article distributed in accordance with the Creative Commons Attribution Non Commercial (CC BY-NC 4.0) license, which permits others to distribute, remix, adapt, build upon this work non-commercially, and license their derivative works on different terms, provided the original work is properly cited and the use is non-commercial. See: http://creativecommons.org/ licenses/by-nc/4.0/

\section{REFERENCES}

1 Tobacco Plain Packaging Act. 2011. http://www.comlaw.gov.au/details/ c2011a00148 (accessed Sept 2014).

2 Competition and Consumer (Tobacco) Information Standard. 2011. http://www. comlaw.gov.au/Details/F2011L02766 (accessed Sept 2014).

3 Scollo M, Lindorff K, Coomber K, et al. Standardised packaging and new enlarged graphic health warnings for tobacco products in Australia-legislative requirements and implementation of the Tobacco Plain Packaging Act 2011 and the Competition and Consumer (Tobacco) Information Standard, 2011. Tob Control 2015;24:ii9-16.

4 Australian Institute of Health and Welfare. 2010 National Drug Strategy Household Survey report. Drug statistics series no. 25. Cat. no. PHE 145. Canberra: AlHW, 2011. http://www.aihw.gov.au/WorkArea/DownloadAsset.aspx?id=10737421314 (accessed Sept 2014).

5 Jamner M. Cigar smoking among college students: prevalence and correlates. Prev Med 1999;29:187-94.

6 Slade J. Marketing and Promotion of cigars (Chapter 7). In: Burns D, Cummings KM, Hoffmann D, eds. Cigars. Health Effects and Trends, Monograph No. 9. USA: Department of Health and Human Services, National Institutes of Health, NIH publication, 1998. http://cancercontrol.cancer.gov/brp/tcrb/monographs/9/m9_ complete.pdf (accessed Sept 2014).
7 Delnevo CD, Hrywna M. Clove cigar sales following the US flavoured cigarette ban. Tob Control Published Online First: 20 March 2014.

8 Cullen J, Mowery P, Delnevo C, et al. Seven-year patterns in US cigar use epidemiology among young adults aged 18-25 years: a focus on race/ethnicity and brand. Am J Public Health 2011;101:1955-62.

9 McNichol T. Cigar asphyxionado. The New York Times, 1997; 29 June.

10 Substance Abuse and Mental Health Services Administration (US). Overview of findings from the 2003 National Survey on Drug Use and Health. Rockville, MD: US Department of Health and Human Services, Substance Abuse and Mental Health Services Administration, Office of Applied Studies, 2004.

11 Wenger L, Malone R, Bero L. The cigar revival and the popular press: a content analysis, 1987-1997. Am J Public Health 2001;91:288-91.

12 Wenger L, Malone R, George A, et al. Cigar magazines: using tobacco to sell a lifestyle. Tob Control 2001;10:279-84.

13 Delnevo CD. Smokers' choice: What explains the steady growth of cigar use in the U.S.? Public Health Report 2006;121:116-19.

14 Parr V, Ell P. Market testing of new health warnings and information messages for tobacco product packaging: Premium cigars, cigarillos/little cigars and roll your own. Sydney, Australia. Prepared for: Australian Department of Health and Ageing, 2011. http://www.health.gov.au/internet/main/ (accessed Sep 2014).

15 Farley SM, Coady MH, Mandel-Ricci J, et al. Public opinions on tax and retail-based tobacco control strategies. Tob Control Published Online First: 23 December 2013.

16 Rosenberg M, Pettigrew S, Wood L, et al. Public support for tobacco control policy extensions in Western Australia: a cross-sectional study. BMJ Open 2012;2: e000784. (accessed Sept 2014).

17 Walsh RA, Paul CL, Tzelepis F, et al. Is government action out-of-step with public opinion on tobacco control? Results of a New South Wales population survey. Aust N Z J Public Health 2008;32:482-8.

18 Wakefield M, Hayes L, Durkin S, et al. Introduction effects of the Australian plain packaging policy on adult smokers: a cross-sectional study. BMJ Open 2013;3: e003175. http:///bmjopen.bmj.com/content/3/7/e003175.full (accessed Sept 2014).

19 Swift E, Borland R, Cummings MK, et al. Australian smokers' support for standardized packs before and after implementation: findings from the ITC Four Country survey. Tob Control Published Online First: 12 November 2014.

20 Cooper J, Borland R, Yong HH, et al. Compliance and support for bans of smoking in licensed venues in Australia: findings from the International Tobacco Control Four Country Survey. Aust N Z I Public Health 2010;20:137-43.

21 Hyland A, Higbee C, Borland R, et al. Attitudes and beliefs about secondhand smoke and smoke-free policies in four countries: findings from the International Tobacco Control Four Country Survey. Nicotine Tob Res 2009;11:642-9.

22 McNeill A, Lewis S, Quinn C, et al. Evaluation of the removal of point-of-sale tobacco displays in Ireland. Tob Control 2011;20:137-43. 